\title{
Effects of endogenous glucocorticoid secretion on the interleukin-6 response to bacterial endotoxin in pregnant and non-pregnant rats
}

\author{
Ke Cui, Giamal N Luheshi and Patricia Boksa \\ Department of Psychiatry, Douglas Mental Health University Institute, McGill University, 6875 LaSalle Boulevard, Montreal, Quebec, Canada H4H 1R3 \\ (Correspondence should be addressed to P Boksa; Email: patricia.boksa@mcgill.ca)
}

\begin{abstract}
Glucocorticoids (GCs) are released in response to immune activation by the bacterial endotoxin, lipopolysaccharide (LPS). However, GC secretion in response to immune activation and other stressors is attenuated at term of pregnancy. GCs are important modulators of the immune response, and both pro- and anti-inflammatory effects are described. Here, we examined whether GC secretion in response to LPS is maintained in earlier pregnancy before term, and investigated the role of endogenous GCs in modulating LPS-induced circulating cytokines, interleukin-6 (IL-6) and tumor necrosis factor- $\alpha$ (TNF- $\alpha$ ), in pregnant compared to non-pregnant female rats. Plasma corticosterone (Cort) and ACTH responses to LPS were well maintained in pregnant rats at embryonic days 15/16 (E15/16) and E18/19 compared to non-pregnant rats. At E19, maternal LPS administration increased fetal plasma Cort and decreased

testosterone in male fetuses. In non-pregnant animals, pretreatment with the GC synthesis inhibitor, metyrapone, inhibited the LPS-induced increase in IL-6, and the IL-6 response was restored by Cort replacement, indicating that LPS induction of IL-6 is Cort-dependent. In E15 pregnant animals, metyrapone had no effect on LPS-induced IL-6 levels, indicating that LPS-induction of IL-6 is not dependent on Cort. These contrasting patterns of IL-6 induction in nonpregnant and pregnant animals were reflected in levels of hypothalamic Socs3 mRNA, an indicator of IL-6 signaling pathway activation. In both non-pregnant and pregnant rats, LPS-induced plasma TNF- $\alpha$ responses were inhibited by metyrapone but not re-instated by Cort replacement. It is suggested that altered GC regulation of IL- 6 may be required to sustain specialized functions of IL-6 during pregnancy.

Journal of Endocrinology (2011) 209, 95-103
\end{abstract}

\section{Introduction}

Effects of prenatal infection on neurodevelopment and other outcomes in offspring are routinely studied using rodent models in which the bacterial endotoxin, lipopolysaccharide (LPS), is administered to dams during mid- to late gestation (Cao et al. 2009, Beloosesky et al. 2010, Boksa 2010). A clear characterization of the acute hormonal and inflammatory responses to endotoxin in the pregnant dam is important, since these responses likely play a role in mediating effects on offspring.

In the non-pregnant animal, immune challenge with either LPS or interleukin-1 $\beta$ (IL-1 $\beta$ ) elicits a prominent acute release of glucocorticoids (GCs), accompanied by an increase in circulating levels of the pro-inflammatory cytokines, IL-6, and tumor necrosis factor (TNF)- $\alpha$ (Beishuizen \& Thijs 2003). These cytokines play a central role in the host defense response to infection, with IL-6 being the most likely main circulating signal to hypothalamic brain areas involved in eliciting fever (Rummel et al. 2006). GCs inhibit cytokine production and release by direct actions on cytokineproducing macrophages and monocytes, and are well known for their classic anti-inflammatory actions
(Almawi et al. 1996). However, it has also become evident that GCs may have either pro- or anti-inflammatory activity depending on various factors such as the dose and timing of GC administration, length of GC exposure, and the preparation studied (cells versus whole organs or animals) (Liao et al. 1995, Sorrells \& Sapolsky 2007, Frank et al. 2010).

GC and ACTH responses to acute physical and psychological stressors are known to be attenuated in the pregnant rat at term (embryonic day 21, E21), compared to responses in non-pregnant controls (Brunton 2010). With respect to immune challenge in pregnancy, Brunton et al. (2005) have shown that E21 pregnant rats show greatly reduced ACTH responses to either i.v. LPS or IL-1 $\beta$ and reduced corticosterone (Cort) secretion in response to IL-1 $\beta$, compared to virgin controls. However, it is unknown whether GC/ACTH responses to immune challenge are maintained at earlier times in gestation. It is also unknown whether GC regulation of cytokine production in pregnancy remains similar to that in the non-pregnant animal.

In the current study, we have examined GC and ACTH responses to immune challenge with LPS at two points in mid- to late gestation (E15-16 and E18-19). Having shown that the LPS-induced GC response is well maintained at E15, 
we investigated the role of LPS-induced GC secretion in modulating production of the cytokines, IL- 6 and TNF- $\alpha$, in E15 pregnant rats compared to non-pregnant rats. This was done by inhibiting GC synthesis with the steroid $11 \beta$-hydroxylase inhibitor, metyrapone, with and without Cort replacement, and testing effects on LPS-induced plasma cytokines.

\section{Materials and Methods}

\section{Animals}

Timed pregnant and non-pregnant female (225-250 g) Sprague-Dawley rats (Charles River Laboratories, Saint Constant, Quebec, Canada) were delivered to our facility 4 days before treatments and housed individually. All animals were maintained at an ambient temperature of $21 \pm 2{ }^{\circ} \mathrm{C}$ on a $12 \mathrm{~h}$ light: $12 \mathrm{~h}$ darkness cycle $(0800-2000 \mathrm{~h})$, with food and water provided ad libitum. All procedures with animals were performed in accordance with guidelines from the Canadian Council on Animal Care and were approved by the McGill University Animal Care Committee.

\section{Study 1}

The first study investigated the effects of LPS on plasma Cort and/or ACTH levels in non-pregnant female rats and in two groups of pregnant rats; the first group of pregnant rats was injected with LPS or saline on E15 and then again on E16, and the second group of pregnant rats was injected with LPS or saline on E18 and E19. Non-pregnant female rats $(n=8$ per experimental group) were administered LPS (Escherichia coli serotype 0111:B4, Sigma, $100 \mu \mathrm{g} / \mathrm{kg}$ ) or saline i.p. once a day for 2 days. Pregnant rats $(n=8)$ received either once daily i.p. injections of $100 \mu \mathrm{g} / \mathrm{kg}$ LPS on E15 and E16, or once daily i.p. injections of $50 \mu \mathrm{g} / \mathrm{kg}$ LPS on E18 and E19; control pregnant rats were administered saline instead of LPS. All injections were administered between 0900 and $1000 \mathrm{~h}$. Doses of LPS were chosen based on our previous work on effects of LPS on survival of pregnant rats and their litters, induction of plasma cytokines, and fever responses (Ashdown et al. 2006, 2007, Fortier et al. 2007, Cui et al. 2009). Tail blood was collected into sterile tubes containing heparin $(10 \mathrm{U} / \mathrm{ml})$ before $(0 \mathrm{~h})$ and at 2,4 , and $6 \mathrm{~h}$ after each LPS or saline injection. Samples were centrifuged $(5300 \mathrm{~g}, 10 \mathrm{~min}$, $4{ }^{\circ} \mathrm{C}$ ), and plasma was collected, aliquoted, and stored at $-80^{\circ} \mathrm{C}$ until assayed for Cort or ACTH.

In a separate experiment, E19 pregnant rats $(n=7-8)$ were injected i.p. with $50 \mu \mathrm{g} / \mathrm{kg}$ LPS or saline. After $4 \mathrm{~h}$, pregnant dams were killed by decapitation, and fetal trunk blood was collected and processed for measurement of Cort and testosterone in fetal plasma. E19 was chosen for this experiment because this later stage of pregnancy allowed for collection of adequate volumes of fetal plasma for assay.
Study 2

The second study investigated the effects of endogenous GC secretion in modulating LPS-induced plasma IL-6 and TNF- $\alpha$ responses in non-pregnant and E15 pregnant rats. This was done by inhibiting GC synthesis with metyrapone, with and without Cort replacement, and testing effects on LPS-induced plasma IL-6, TNF- $\alpha$ and Cort, and hypothalamic suppressor of cytokine signaling 3 (Socs3) mRNA, an indicator of IL-6 signaling pathway activation. Non-pregnant female and E15 pregnant rats ( $n=7-8$ /experimental group) were injected i.p. with metyrapone $(75 \mathrm{mg} / \mathrm{kg})$ or its vehicle ( $40 \%$ propylene glycol in saline, $1 \mathrm{ml} / \mathrm{kg}$ ) at $0800 \mathrm{~h}$. An i.p. injection of LPS $(100 \mu \mathrm{g} / \mathrm{kg})$ or saline followed by a s.c. injection of Cort $(30 \mathrm{mg} / \mathrm{kg})$ or its vehicle $(30 \%$ ethanol, $2 \mathrm{ml} / \mathrm{kg}$ ) was given at $1100 \mathrm{~h}$. For both non-pregnant female rats and E15 pregnant rats, there were four treatment groups: 1) $\mathrm{Veh}+\mathrm{Sal}+\mathrm{Veh}$, administered vehicle for metyrapone, saline, and vehicle for Cort; 2) Veh + LPS + Veh, administered vehicle for metyrapone, LPS, and vehicle for Cort; 3) Met + LPS + Veh, administered metyrapone, LPS, and vehicle for Cort; 4) Met +LPS + Cort, administered metyrapone, LPS, and Cort. Tail blood was collected into heparinized tubes before $(0 \mathrm{~h})$ and at 1 and $2 \mathrm{~h}$ after LPS or saline injection, and plasma was stored at $-80^{\circ} \mathrm{C}$ for measurement of Cort, IL-6, and TNF- $\alpha$. At $3 \mathrm{~h}$ after LPS or saline, animals were deeply anaesthetized (ketamine/xylazine/acepromazine, $50 / 5 / 0 \cdot 5 \mathrm{mg} / \mathrm{kg}$ ) and perfused with sterile saline. Hypothalami were dissected, frozen on dry ice, and stored at $-80{ }^{\circ} \mathrm{C}$ until used for measurement of Socs 3 mRNA.

\section{Plasma Cort, testosterone, ACTH, IL-6, and TNF- $\alpha$ assays}

All samples and standards were assayed in duplicate. Plasma Cort and testosterone were assayed using RIA kits from MP Biomedicals (Orangeburg, NY, USA) and plasma ACTH using a RIA kit from Diasorin (Stillwater, MN, USA). Lower limits of assay sensitivities were $12.5 \mathrm{ng} / \mathrm{ml}$ for Cort, $25 \mathrm{pg} / \mathrm{ml}$ for testosterone, and $15 \mathrm{pg} / \mathrm{ml}$ for ACTH. Plasma IL-6 and TNF- $\alpha$ were assayed as described previously (Cui et al. 2009) using two-site, rat-specific ELISAs kindly provided by Stephen Poole (National Institute for Biological Standards and Control, Potters Bar, UK). Intra-and interassay coefficients of variability were $<10 \%$ for all assays. The detection limits were $15 \mathrm{pg} / \mathrm{ml}$ for both IL-6 and TNF- $\alpha$.

\section{Quantitative reverse transcriptase-PCR}

For measurement of Socs 3 mRNA and 18S rRNA, the hypothalamus was homogenized in TriZol (Invitrogen) to extract total RNA. Total isolated RNA was dissolved in $40 \mu \mathrm{l}$ diethylpyrocarbonate-treated water. In total, $1 \mu \mathrm{g}$ RNA was incubated with $5 \mu \mathrm{M}$ random hexamers (Applied Biosystems, Streetsville, Ontario, Canada) and $1 \mathrm{mM}$ dNTPs (SigmaAldrich) in a Gene Amp PCR System 9700 Thermocycler (Applied Biosystems) at $65^{\circ} \mathrm{C}$ for $10 \mathrm{~min}$. cDNA synthesis was 
performed by adding dithiothreitol (Invitrogen), murine myeloid leukemia virus reverse transcriptase (Invitrogen), and first-strand buffer (Invitrogen) and further incubating in the thermocycler at $37^{\circ} \mathrm{C}$ for $1 \mathrm{~h}$ and then at $90^{\circ} \mathrm{C}$ for $5 \mathrm{~min}$ in a total volume of $20 \mu \mathrm{l}$. The cDNA product was diluted to $200 \mu \mathrm{l}$ with autoclaved distilled water, and amplified in duplicate by quantitative real-time PCR using a 7500 Real-Time PCR System (Applied Biosystems). Each sample contained $2 \mu \mathrm{l}$ prepared cDNA, $1 \mu \mathrm{l}$ primer/probe mixture (20X; Applied Biosystems), and $10 \mu \mathrm{l}$ TaqMan PCR master mix (Applied Biosystems) in a volume of $20 \mu \mathrm{l}$. Each hypothalamic sample was assayed for Socs3 gene expression (primer ID \# RN00585674_s1). The housekeeping gene 18S rRNA (primer ID \# EUK-rRNA4352930) was used to normalize the levels of cDNA expression for each sample.

\section{Statistical analyses}

All data are presented as mean values + S.E.M. and were analyzed with GraphPad Prism 4 (GraphPad Software, Inc.,
La Jolla, CA, USA). Data for plasma Cort, ACTH, IL-6, and TNF- $\alpha$ in non-pregnant and pregnant rats were analyzed using two-way ANOVA with treatment as between-subject factor and sampling time point as within-subject factor, followed by Bonferroni post-hoc tests. One-way ANOVA was used to analyze hypothalamic Socs 3 mRNA data, and an unpaired $t$-test was used for data on fetal plasma Cort and testosterone after LPS or saline treatment of their dams. Probabilities of $P<0 \cdot 05$ were considered significant.

\section{Results}

Figure 1A shows plasma Cort levels at 0, 2, 4, and $6 \mathrm{~h}$ after injection of LPS or saline to pregnant rats at E15-16 or E18-19 and to control non-pregnant female rats. LPS at a dose of $100 \mu \mathrm{g} / \mathrm{kg}$ was administered to pregnant rats on E15 and again on E16, and to non-pregnant rats on two consecutive days; this dose of LPS reliably induces cytokine release and fever with $100 \%$ dam survival in the E15 pregnant

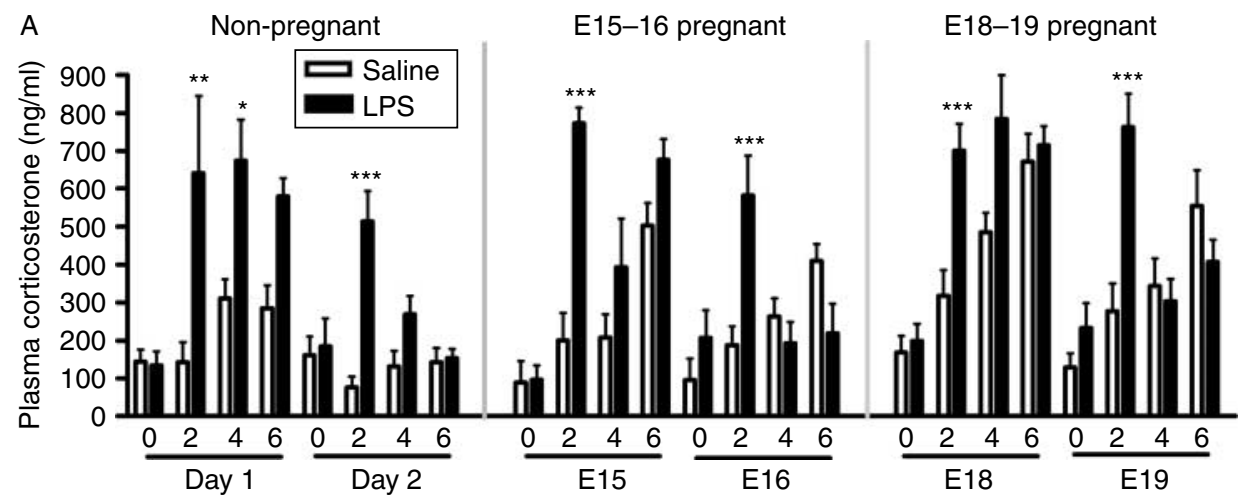

Hours after LPS or saline injection
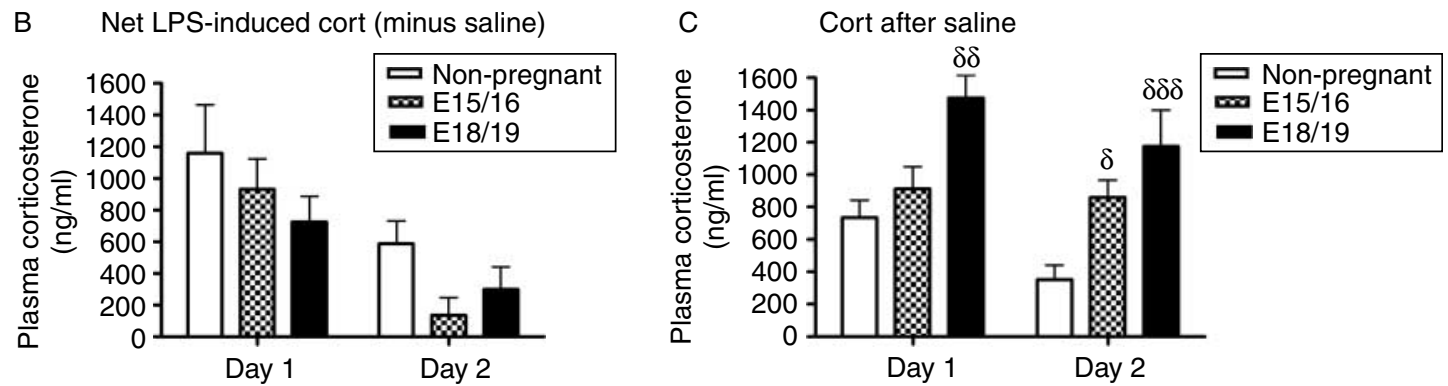

Figure 1 Plasma corticosterone responses to lipopolysaccharide in non-pregnant and pregnant rats. Lipopolysaccharide (LPS) or saline (Sal) was administered once daily on two consecutive days to non-pregnant female rats, to pregnant rats on E15 and E16, or to pregnant rats on E18 and E19. The dose of LPS for non-pregnant rats and for E15/E16 pregnant rats was $100 \mu \mathrm{g} / \mathrm{kg}$, while E18/E19 pregnant rats received $50 \mu \mathrm{g} / \mathrm{kg}$ LPS due to the increased sensitivity to lethal effects of LPS in rats in late gestation. A shows plasma corticosterone (Cort) levels at various times after LPS or saline injection. Significantly different from saline at $* * * P<0 \cdot 001,{ }^{* *} P<0 \cdot 01$, and $* P<0 \cdot 05$. B and C are derived from the data in (A). In (B), to compare the magnitude of LPS-induced Cort secretion across groups, net LPS-induced Cort was calculated by subtracting the average value for saline-induced Cort from the value for LPS-induced Cort for each animal. The resulting net LPS-induced Cort values for 2,4 , and $6 \mathrm{~h}$ were summed and are shown for each treatment day. There were no significant differences in net LPS-induced Cort between nonpregnant, E15/E16 pregnant, and E18/E19 pregnant animals on either day. In (C), to compare the magnitude of saline-induced Cort secretion across groups, saline-induced Cort values for 2, 4, and $6 \mathrm{~h}$ were summed and are shown for each treatment day. Significantly different from non-pregnant rats at ${ }^{\delta} P<0 \cdot 001,{ }^{\delta \delta} P<0 \cdot 01$, and ${ }^{\delta \delta \delta} P<0 \cdot 05$. All results are means + S.E.M. from eight animals/group. 


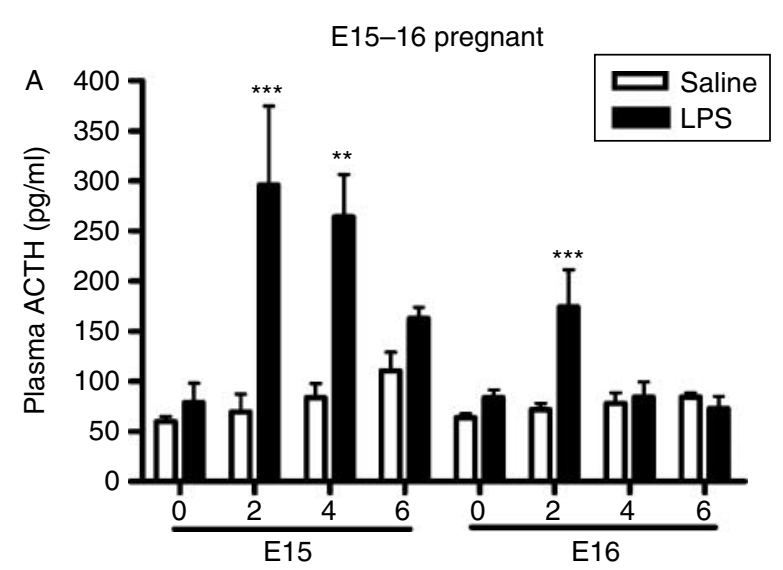

Hours after LPS or saline injection

E18-19 pregnant

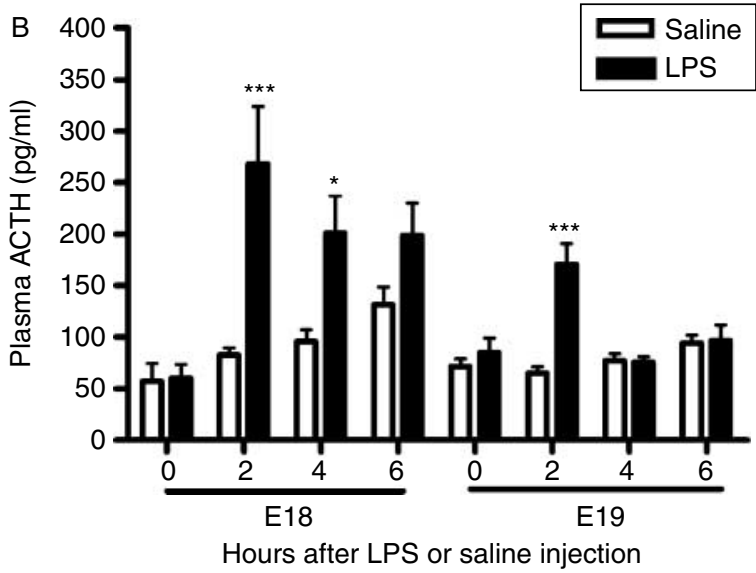

Figure 2 Plasma ACTH responses to lipopolysaccharide in pregnant rats. Pregnant rats received once daily injections of $100 \mu \mathrm{g} / \mathrm{kg}$ lipopolysaccharide (LPS) or saline (Sal) on E15 and E16 in (A), or $50 \mu \mathrm{g} / \mathrm{kg}$ LPS or saline on E18 and E19 in (B). Plasma ACTH levels at various times after LPS or saline injection are shown. Results are means + S.E.M. from seven animals/group. Significantly different from saline at ${ }^{* * *} P<0 \cdot 001,{ }^{* *} P<0 \cdot 01$, and ${ }^{*} P<0 \cdot 05$.

rat (Fortier et al. 2007, Cui et al. 2009). Rats at the later stage of pregnancy were administered a lower dose of $50 \mu \mathrm{g} / \mathrm{kg}$ LPS on E18 and again on E19. The lower dose was used because late pregnancy is associated with increased sensitivity to the lethal effects of LPS (Martin et al. 1995); in our hands, $50 \mu \mathrm{g} / \mathrm{kg}$ LPS induces cytokine release and fever in the E18 pregnant rat and yields survival of $62 \%$ of dams (Ashdown et al. 2006, 2007, Fortier et al. 2007). In non-pregnant rats, LPS induced a significant increase in plasma Cort compared to saline at 2 and $4 \mathrm{~h}$ on day 1 , and at $2 \mathrm{~h}$ on day 2 (Fig. 1A). The lesser Cort secretion on day 2 compared to day 1 is likely a result of the well-known phenomenon of endotoxin tolerance (Biswas \& Lopez-Collazo 2009). In both E15-16 and E18-19 pregnant rats, LPS induced a significant increase in plasma Cort compared to saline at $2 \mathrm{~h}$ on days 1 and 2 . To better compare the magnitude of LPS-induced Cort secretion among groups, average Cort levels after saline were subtracted from Cort levels after LPS, and the resulting values for net LPS-induced Cort were summed for 2, 4, and $6 \mathrm{~h}$ on each day (Fig. 1B). Although levels tended to be lower in the pregnant compared to non-pregnant animals, there were no significant differences in net LPS-induced Cort levels among E15-16 pregnant, E18-19 pregnant and non-pregnant rats on either day 1 or 2 . The tendency for reduced net LPS-induced Cort secretion in the pregnant groups could be accounted for in part by an increase in saline-induced Cort in the pregnant animals. Figure $1 \mathrm{C}$ shows that, compared to non-pregnant rats, E15-16 pregnant animals had significantly increased Cort after saline on day 2, while E18-19 pregnant animals showed increased Cort after saline on both days 1 and 2 . This increase in saline-induced Cort in pregnancy may be due in part to the progressive increase in basal Cort reported to occur from mid-pregnancy to term (Brunton 2010). Figure 2 shows that, in both E15-16 and E18-19 pregnant rats, LPS also induced a significant increase in plasma ACTH compared to saline at 2 and $4 \mathrm{~h}$ on day 1 and at $2 \mathrm{~h}$ on day 2 .

To determine whether fetal Cort levels are affected when maternal Cort levels increase in response to LPS, we measured fetal plasma Cort after administration of LPS to rat dams on E19. Cort levels in fetal plasma were significantly increased $4 \mathrm{~h}$ after maternal LPS injection (Fig. 3A). Since GCs are well documented to inhibit testosterone production in the fetal rat during late gestation (Scott et al. 2009), we also tested for changes in fetal plasma testosterone after maternal LPS as a possible downstream consequence of increased fetal Cort. Plasma testosterone levels were significantly decreased in male fetuses $4 \mathrm{~h}$ after maternal LPS injection on E19 (Fig. 3B). Plasma testosterone levels in female fetuses were low and unaffected by maternal LPS treatment.

To investigate the role of GCs in modulating cytokine levels in response to LPS, groups of non-pregnant and E15 pregnant rats were administered saline, LPS, or LPS with metyrapone, an inhibitor of GC synthesis, and plasma levels of Cort and the cytokines, IL-6 and TNF- $\alpha$, were measured. To confirm whether effects of metyrapone were due to
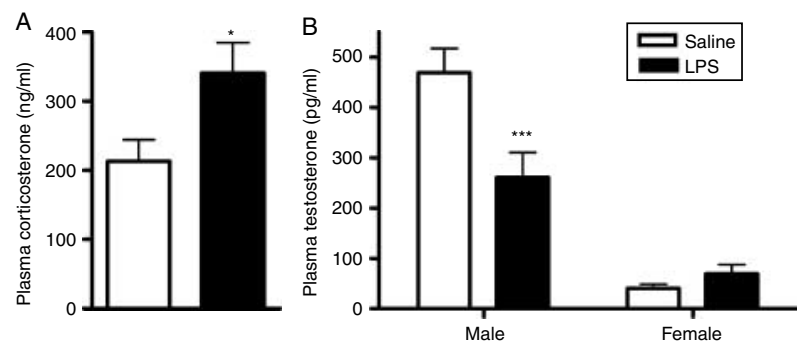

Figure 3 Corticosterone and testosterone in fetal plasma after maternal LPS or saline administration on E19. E19 pregnant rats were administered lipopolysaccharide (LPS, $50 \mu \mathrm{g} / \mathrm{kg}$ ) or saline (Sal). Four hours later, fetal blood was collected for measurement of plasma corticosterone (A) and testosterone (B). For testosterone, blood from male and female fetuses was collected separately. Results are mean values + S.E.M. for plasma samples from fetuses from seven to eight separate dams/group. Significantly different from saline at ${ }^{* * *} P<0.001$ and $* P<0 \cdot 05$. 
inhibition of GC production, additional groups of nonpregnant and E15 pregnant animals were treated with LPS and metyrapone, and Cort was replaced by administering exogenous Cort. Figure 4 shows plasma Cort levels in these groups of animals at 1 and $2 \mathrm{~h}$ after LPS or saline administration. As expected, in both non-pregnant and E15 pregnant animals at 1 and $2 \mathrm{~h}$, LPS induced a significant increase in plasma Cort levels compared to saline, and this LPS-induced increase in Cort was completely inhibited by metyrapone. Also in both non-pregnant and E15 pregnant animals, Cort $(30 \mathrm{mg} / \mathrm{kg})$ replacement, in the presence of LPS and metyrapone, produced plasma Cort levels that were

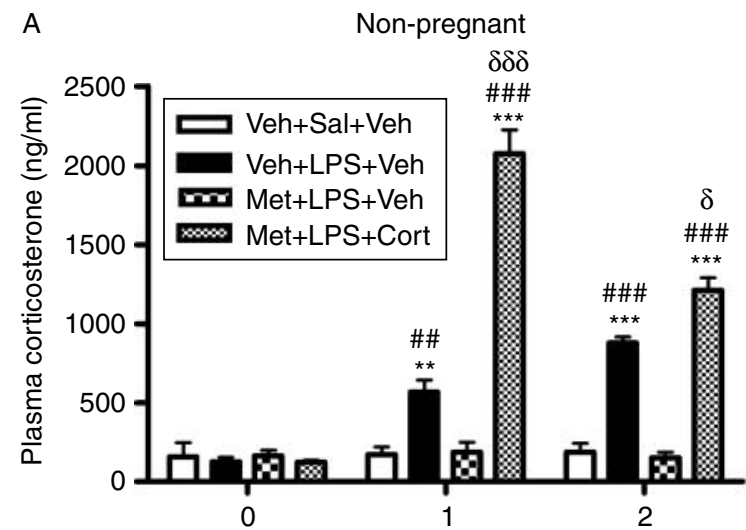

Hours after LPS or saline injection

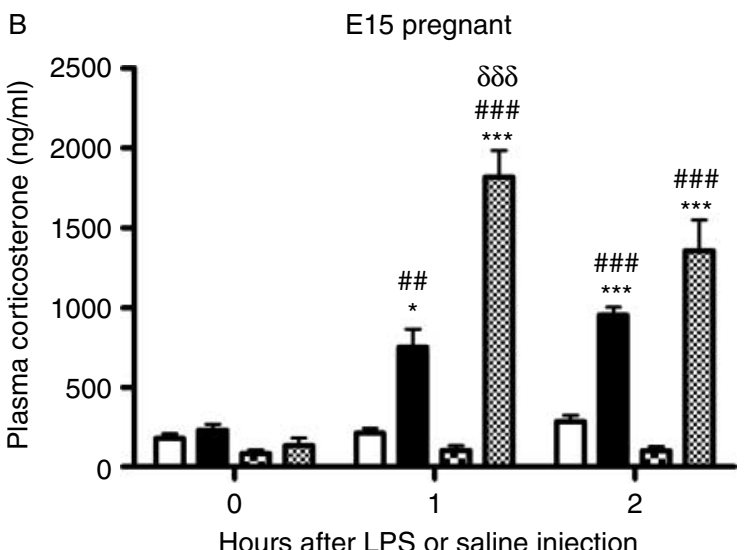

Figure 4 Plasma corticosterone responses to lipopolysaccharide after metyrapone pretreatment and corticosterone replacement in non-pregnant and E15 pregnant rats. Non-pregnant female and E15 pregnant rats were treated with metyrapone (Met, $75 \mathrm{mg} / \mathrm{kg}$ ) or vehicle (Veh). Three hours later, rats were administered lipopolysaccharide (LPS, $100 \mu \mathrm{g} / \mathrm{kg}$ ) or saline (Sal), followed immediately by corticosterone (Cort, $30 \mathrm{mg} / \mathrm{kg}$ ) or vehicle. Plasma Cort levels at various times after LPS or saline injection are shown. Results are means + S.E.M. from eight animals/group. Significantly different from Veh + Sal + Veh at $* * * P<0 \cdot 001,{ }^{* *} P<0 \cdot 01$, and $* P<0 \cdot 05$. Significantly different from Met + LPS + Veh at ${ }^{\# \#} P<0 \cdot 001$ and $\#^{\#} P<0 \cdot 01$. Significantly different from Veh + LPS + Veh at

${ }^{\delta \delta \delta} P<0 \cdot 001$ and ${ }^{\delta} P<0 \cdot 05$. higher than those induced by LPS at $1 \mathrm{~h}$, but were near to the levels induced by LPS at $2 \mathrm{~h}$.

Having confirmed inhibition of LPS-induced Cort secretion by metyrapone and replacement by exogenous Cort, we measured plasma IL-6 in the same treatment groups at 1 and $2 \mathrm{~h}$ after LPS or saline (Fig. 5A and B). To test whether modulation of IL- 6 is reflected in brain inflammatory signals mediated by IL-6, we also measured hypothalamic mRNA for SOCS3, a product of the signal transducer and activator of transcription 3 (STAT3) pathway that is activated by IL-6, in groups of similarly treated animals, at $3 \mathrm{~h}$ after LPS or saline administration (Fig. 5C and D). In both non-pregnant and E15 pregnant animals, LPS induced significant increases in plasma IL-6 at $2 \mathrm{~h}$. In non-pregnant animals, metyrapone completely inhibited the increase in IL-6 induced by LPS, and IL-6 induction by LPS in the presence of metyrapone was restored by Cort replacement, indicating that LPS induction of IL-6 is dependent on Cort (Fig. 5A). In contrast, in E15 pregnant animals, IL-6 levels were similar in groups of animals treated with LPS or LPS + metyrapone or LPS + metyrapone + Cort replacement (Fig. 5B). Thus, metyrapone had no effect on LPS-induced IL-6 levels, indicating that LPS induction of IL-6 is not dependent on Cort in E15 pregnant rats. These contrasting patterns of IL-6 induction in non-pregnant and pregnant animals were reflected in hypothalamic Socs 3 mRNA. In non-pregnant animals, LPS induced a significant increase in Socs 3 mRNA; this induction was inhibited in the presence of metyrapone, and restored by Cort replacement (Fig. 5C). In E15 pregnant animals, hypothalamic Socs 3 mRNA levels were significantly increased in groups treated with LPS or LPS + metyrapone or LPS + metyrapone + Cort, compared to levels in vehicle-treated controls (Fig. 5D).

Figure 6 shows effects of LPS with or without metyrapone and Cort replacement on plasma TNF- $\alpha$ in non-pregnant rats compared to E15 pregnant rats. In contrast to results for IL-6, the effects of metyrapone and Cort replacement on TNF- $\alpha$ responses to LPS were similar in non-pregnant and pregnant rats. In both non-pregnant and E15 pregnant animals, LPS induced significant increases in plasma TNF- $\alpha$ at both 1 and $2 \mathrm{~h}$ after LPS injection, and these LPS-induced increases in TNF- $\alpha$ were completely inhibited by metyrapone. However, Cort replacement did not reverse metyrapone's inhibition of LPS-induced TNF- $\alpha$ production, indicating that metyrapone's effects here are due to other mechanisms than inhibition of Cort synthesis.

\section{Discussion}

The first main finding of this study is that plasma Cort and ACTH responses to LPS are well maintained in E15/16 and E18/19 pregnant rats compared to responses in non-pregnant female rats. Recent findings on the mechanism by which LPS stimulates GC release indicate that binding of LPS to Toll-like receptors (TLR) on endothelial cells of the brain 
microvasculature induces production and release of prostaglandin E2, leading to activation of EP3 receptors on GABAergic afferents to the paraventricular nucleus. This causes disinhibition of corticotropin-releasing factor (CRF) neurons, and therefore increased release of CRF, ACTH, and GCs (Rivest 2010). These mechanisms appear to be functional in E15/16 and E18/19 pregnant rats. In contrast,

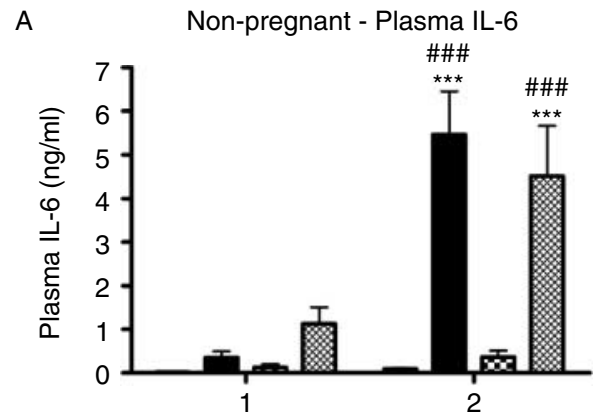

Hours after LPS or saline injection

B

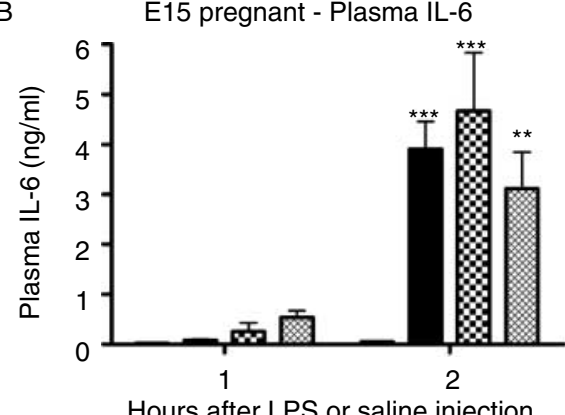

C Non-pregnant - Hypothalamic Socs3 mRNA
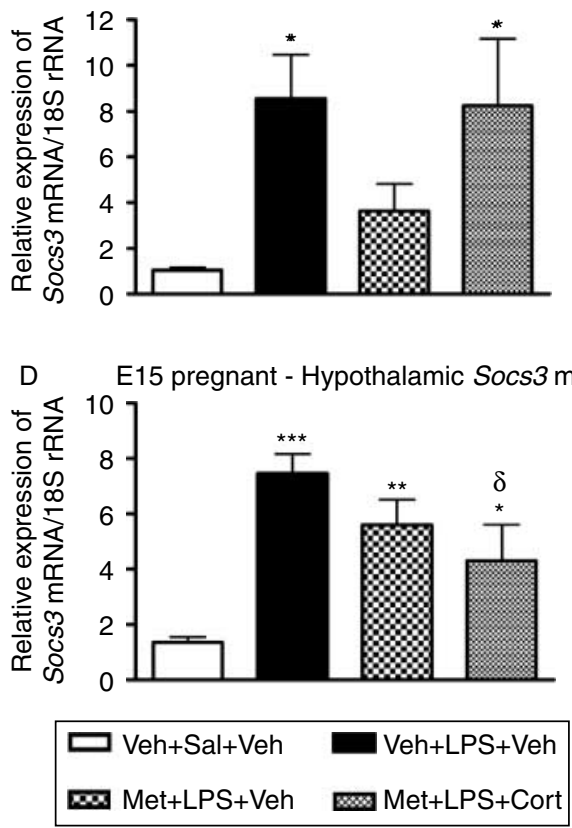

Journal of Endocrinology (2011) 209, 95-103 the plasma ACTH response to i.v. LPS, and plasma ACTH and Cort responses to i.v. IL-1 $\beta$, are reported to be absent in rats later in pregnancy, at E21 (Brunton et al. 2005). Thus, it appears that within a narrow window between E19 and E21, ACTH and Cort responses to immune challenge are suppressed. Brunton et al. (2005) provided evidence that the lack of ACTH/Cort response to IL-1 $\beta$ at E21 involves reduced stimulation of hypothalamic CRF neurons by brainstem noradrenergic inputs from the nucleus tractus solitarius (NTS), due to enhanced opioid inhibition of noradrenaline release. This enhanced opioid inhibition may be driven by increased brain levels of the progesterone metabolite, allopregnanolone, which peak at E19 and lead to enhanced pro-enkephalin expression in the NTS (Brunton 2010).

At E19, we found that LPS-induced increases in systemic Cort in the mother are reflected by increased plasma Cort in the fetus. Although the Cort metabolizing enzyme, $11 \beta-$ hydroxysteroid dehydrogenase type 2 (11 $\beta$-HSD2), is thought to provide a partial barrier preventing maternal to fetal transport of Cort, placental 11ß-HSD2 decreases during the last third of gestation in the rat (Vagnerová et al. 2008), and prenatal stress can also down-regulate placental $11 \beta-H S D 2$ activity (Mairesse et al. 2007). Thus, increased fetal Cort after maternal LPS may be of maternal origin, since Cort can be transplacentally transported in the rodent (Vagnerová et al. 2008). Fetal plasma Cort may also be partially fetal in origin, since rodent fetal adrenals become competent to produce Cort late in gestation (Dupouy et al. 1975). Maternal LPS also decreased plasma testosterone in male fetuses on E19, a time when male rat fetuses experience a testosterone surge that plays an important role in the development of male reproductive physiology (Wilson \& Davies 2007). Since GCs have been shown to depress fetal testosterone production (Scott et al. 2009), decreased fetal testosterone may be due in part to increased Cort after maternal LPS treatment.

Exogenous GCs are most often recognized for their therapeutic anti-inflammatory effects. However, permissive effects are also observed depending on the dose and timing of GC administration, indicating that GCs play a bidirectional role in regulating the inflammatory response. For example, low, physiologic doses of Cort have been demonstrated to

Figure 5 Plasma interleukin-6 and hypothalamic Socs3 mRNA responses to lipopolysaccharide after metyrapone pretreatment and corticosterone replacement in non-pregnant and E15 pregnant rats. Non-pregnant female and E15 pregnant rats were treated with metyrapone (Met, $75 \mathrm{mg} / \mathrm{kg}$ ) or vehicle (Veh). Three hours later, rats were administered lipopolysaccharide (LPS, $100 \mu \mathrm{g} / \mathrm{kg}$ ) or saline (Sal), followed immediately by corticosterone (Cort, $30 \mathrm{mg} / \mathrm{kg}$ ) or vehicle. A and B show plasma interleukin-6 (IL-6) levels at 1 and $2 \mathrm{~h}$ after LPS or saline injection, and results are means +S.E.M. from seven to eight animals/group. C and D show hypothalamic suppressor of cytokine signaling 3 (Socs3) mRNA levels at $3 \mathrm{~h}$ after LPS or saline injection, and results are means + S.E.M. from six animals/group. Significantly different from Veh + Sal + Veh at

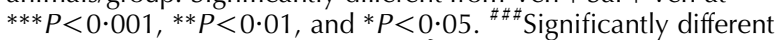
from Met $+\mathrm{LPS}+$ Veh at $P<0 \cdot 001 .{ }^{\delta}$ Significantly different from Veh + LPS + Veh at $P<0 \cdot 05$ 
enhance IL-6 and TNF- $\alpha$ release in response to LPS, while higher doses of Cort inhibited IL-6 release (Liao et al. 1995, Zhang \& Daynes 2007). With respect to timing, administration of Cort to rats $2 \mathrm{~h}$ before LPS enhanced liver $I L-6$ and TNF- $\alpha$ mRNA in response to LPS, while Cort given $1 \mathrm{~h}$ after LPS inhibited these responses (Frank et al. 2010).

In our study, we examined the role of endogenous Cort release in regulating IL- 6 and TNF- $\alpha$ responses to LPS, by inhibiting GC synthesis with metyrapone and then replacing Cort. Our results indicate that, in non-pregnant female control rats, the plasma IL-6 response to LPS is Cortdependent since it was both inhibited by metyrapone and re-instated by Cort replacement. However, we did not find similar evidence that the TNF- $\alpha$ response was Cortdependent. In non-pregnant female rats, the increase in plasma TNF- $\alpha$ induced by LPS was inhibited by metyrapone but not re-instated by Cort replacement, suggesting that metyrapone's inhibition of LPS-induced TNF- $\alpha$ is due to an effect of metyrapone other than blockade of GC synthesis. Other effects of metyrapone may be related to its welldocumented ability to bind to and inhibit cytochrome P450 (Gower 1974, Fantuzzi et al. 1993). The differing effects of metyrapone on IL- 6 versus TNF- $\alpha$ responses suggest that production or metabolism of these two cytokines may be differentially regulated following LPS administration.

Previous work has studied effects of endogenous Cort on cytokine responses by eliminating Cort effects using adrenalectomy in male rats or mice. TNF- $\alpha$ has been studied more often than IL-6. Perretti et al. (1993) and Pettipher et al. (1996) found that adrenalectomy increased LPS-induced plasma TNF- $\alpha$, but both groups concluded that Cort does not modulate TNF- $\alpha$ release since the GC/progesterone receptor inhibitor, RU 486, had no effect. Pettipher et al. (1996) also found that propranolol had the same effect as adrenalectomy, suggesting that effects of adrenalectomy on TNF- $\alpha$ were due to loss of adrenaline, not Cort. Other groups found that adrenalectomy either increased (Le Contel et al. 1995) or had no effect (Morrow et al. 1993, Meltzer et al. 2003) on LPS-induced plasma TNF- $\alpha$. With respect to IL-6, several groups reported that adrenalectomy increases LPS-induced plasma IL-6 (Morrow et al. 1993, Schöbitz et al. 1993, Le Contel et al. 1995). However, two of these studies did not examine whether Cort could reverse the effects of adrenalectomy (Morrow et al. 1993, Le Contel et al. 1995). The study by Schöbitz et al. (1993) did report that Cort reversed effects of adrenalectomy; however, their data show that there were no significant differences in plasma Cort between control, adrenalectomized, and adrenalectomized + Cort replacement groups at the time LPS-induced IL-6 was measured. In our experiments, reversal of metyrapone's effects by Cort replacement strongly supports the conclusion that LPS-induced IL-6 release is Cort-dependent in nonpregnant female rats.

Another main finding of this study is that there are differential effects of GCs on IL-6 responses in pregnant compared to non-pregnant rats. In E15 pregnant rats, the increase in plasma IL-6 induced by LPS was unaffected when GC release was inhibited by metyrapone. Thus, the LPSinduced IL-6 response was independent of Cort in pregnant rats, while this response was Cort-dependent in control nonpregnant animals. Activation of IL-6 receptors present in the hypothalamus (Benrick et al. 2009) by IL-6 induces expression of SOCS3 via activation of the janus kinase (JAK)-STAT3 pathway (Auernhammer \& Melmed 2001). In our study, hypothalamic Socs 3 mRNA induction correlated with IL-6 levels. In pregnant rats, LPS-induced Socs3 expression was not inhibited by metyrapone pretreatment, while in non-pregnant controls, metyrapone inhibited the LPS-induced increase in Socs 3 mRNA, and metyrapone's effect was reversed by Cort replacement. Thus, functional consequences of GC regulation of circulating IL-6 levels were observed at the level of hypothalamic Socs 3 expression.

Induction of cytokines by LPS involves binding of LPS to TLR4, which activates nuclear factor kappa B (NFkB) and
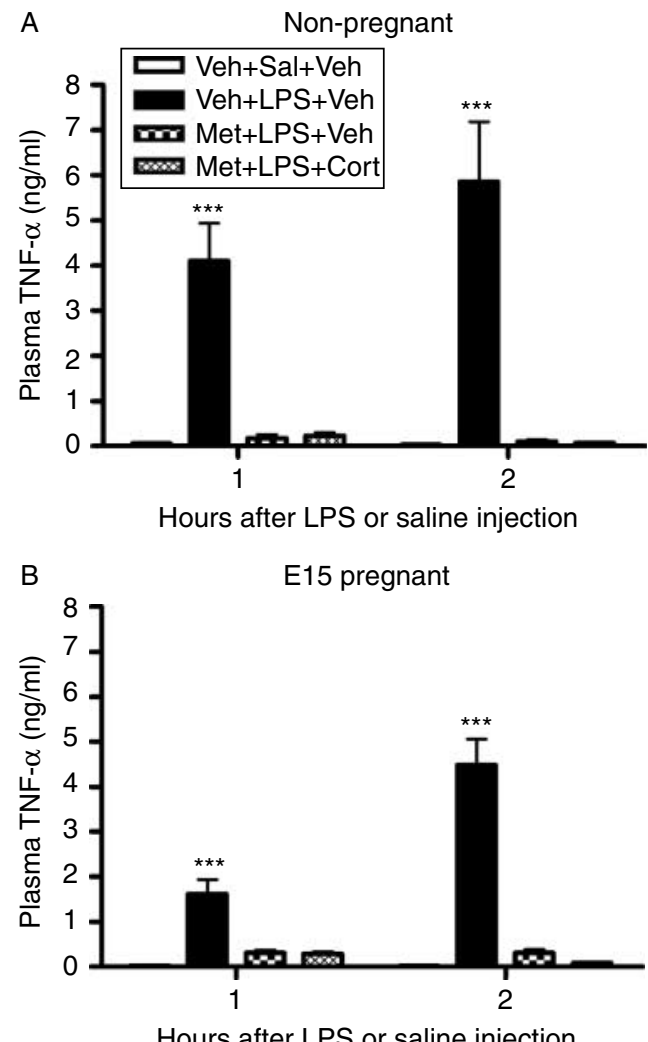

Figure 6 Plasma tumor necrosis factor- $\alpha$ responses to lipopolysaccharide after metyrapone pretreatment and corticosterone replacement in non-pregnant and E15 pregnant rats. Non-pregnant female and E15 pregnant rats were treated with metyrapone (Met, $75 \mathrm{mg} / \mathrm{kg}$ ) or vehicle (Veh). Three hours later, rats were administered lipopolysaccharide (LPS, $100 \mu \mathrm{g} / \mathrm{kg}$ ) or saline (Sal), followed immediately by corticosterone (Cort, $30 \mathrm{mg} / \mathrm{kg}$ ) or vehicle. Plasma tumor necrosis factor- $\alpha$ (TNF- $\alpha$ ) levels at 1 and $2 \mathrm{~h}$ after LPS or saline injection are shown. Results are means + S.E.M. from seven to eight animals/group. ${ }^{* * *}$ Significantly different from all other treatment groups at $P<0 \cdot 001$. 
mitogen-activated protein kinase (MAPK) signaling pathways mediating cytokine production in macrophages and other immune cells ( $\mathrm{Lu}$ et al. 2008). In vitro studies have demonstrated that GCs can promote up-regulation of TLR 4 and TLR2, activation of NFkB and MAPK signaling, and overexpression of inflammatory cytokines (Hermoso et al. 2004, Rozkova et al. 2006, Zhang \& Daynes 2007, Shibata et al. 2009). GCs may induce TLR2 gene expression via a $3^{\prime}$ GC response element (GRE)-like element present on the TLR promoter (Hermoso et al. 2004) and/or induction of MAPK phosphatase-1 leading to suppression of p38 MAPK activity (Shibata et al. 2009). GCs may also increase TLR4 signaling by down-regulating the phosphatidylinositol 3-kinase-AKT (PI3K-AKT) pathway, which serves as a negative regulator of TLR signaling (Zhang \& Daynes 2007).

The mechanisms that cause the IL-6 response to LPS to become independent of GC regulation during pregnancy remain to be elucidated. However, one can speculate that high levels of circulating progesterone occurring during pregnancy may play a role. Plasma progesterone levels increase during pregnancy in the rat, peaking at E15-E20 before falling prior to birth (Bridges 1984). In addition to its own receptors, progesterone can signal through GC receptors (Jones et al. 2008). Thus, it is possible that progesterone may substitute for Cort at GC-responsive sites in facilitating LPSinduced IL-6 responses in the pregnant rat. Alternatively, the high levels of progesterone present in pregnancy may act via progesterone receptors and have unique effects on IL-6 responses. For example, Simhan et al. (2008) have recently shown that treatment of human decidual cells with progestin prior to LPS exposure increases expression of caspase 8, a necessary component for TLR-induced NFkB activation, suggesting that progestins could prime NFkB-mediated immune responses, such as IL-6 induction, in some tissues. Another possibility is that during pregnancy there are unique tissue sources of IL-6, which are not dependent on GC regulation. For example, administration of LPS to pregnant rat dams has been shown to increase placental IL-6, which may contribute to IL-6 in maternal circulation (Urakubo et al. 2001, Ashdown et al. 2006).

It is known that cytokines play a role in several aspects of normal pregnancy. For example, IL-6 is thought to participate in a paracrine regulatory network regulating placental growth during mid- to late gestation (Bowen et al. 2002), and has been shown to modulate expression of genes involved in uterine activation during pregnancy (Robertson et al. 2010). It is possible that altered GC regulation of IL-6 responses may be required to sustain these specialized functions of IL-6 during pregnancy.

\section{Declaration of interest}

The authors declare that there is no conflict of interest that could be perceived as prejudicing the impartiality of the research reported.

\section{Funding}

This work was supported by the Canadian Institutes of Health Research (grant number 80228).

\section{Acknowledgements}

We would like to acknowledge expert technical assistance from Dominique Nouel and Ying Zhang in completing this work.

\section{References}

Almawi WY, Beyhum HN, Rahme AA \& Rieder MJ 1996 Regulation of cytokine and cytokine receptor expression by glucocorticoids. Journal of Leukocyte Biology 60 563-572.

Ashdown H, Dumont Y, Ng M, Poole S, Boksa P \& Luheshi GN 2006 The role of cytokines in mediating effects of prenatal infection on the fetus: implications for schizophrenia. Molecular Psychiatry 11 47-55. (doi:10.1038/ sj.mp.4001748)

Ashdown H, Poole S, Boksa P \& Luheshi GN 2007 Interleukin-1 receptor antagonist as a modulator of gender differences in the febrile response to lipopolysaccharide in rats. American Journal of Physiology 292 R1667-R1674. (doi:10.1152/ajpregu.00274.2006)

Auernhammer CJ \& Melmed S 2001 The central role of SOCS-3 in integrating the neuro-immunoendocrine interface. Journal of Clinical Investigation 108 1735-1740. (doi:10.1172/JCI14662)

Beishuizen A \& Thijs LG 2003 Endotoxin and the hypothalamo-pituitaryadrenal (HPA) axis. Journal of Endotoxin Research 9 3-24. (doi:10.1177/ 09680519030090010101)

Beloosesky R, Maravi N, Weiner Z, Khatib N, Awad N, Boles J, Ross MG \& Itskovitz-Eldor J 2010 Maternal lipopolysaccharide-induced inflammation during pregnancy programs impaired offspring innate immune responses. American Journal of Obstetrics and Gynecology 203 185.e1-185.e4. (doi:10. 1016/j.ajog.2010.04.033)

Benrick A, Schéle E, Pinnock SB, Wernstedt-Asterholm I, Dickson SL, Karlsson-Lindahl L \& Jansson JO 2009 Interleukin-6 gene knockout influences energy balance regulating peptides in the hypothalamic paraventricular and supraoptic nuclei. Journal of Neuroendocrinology 21 620-628. (doi:10.1111/j.1365-2826.2009.01879.x)

Biswas SK \& Lopez-Collazo E 2009 Endotoxin tolerance: new mechanisms, molecules and clinical significance. Trends in Immunology 30 475-487. (doi:10.1016/j.it.2009.07.009)

Boksa P 2010 Effects of prenatal infection on brain development and behavior: a review of findings from animal models. Brain, Behavior, and Immunity 24 881-897. (doi:10.1016/j.bbi.2010.03.005)

Bowen JM, Chamley L, Keelan JA \& Mitchell MD 2002 Cytokines of the placenta and extra-placental membranes: roles and regulation during human pregnancy and parturition. Placenta 23 257-273. (doi:10.1053/plac. 2001.0782)

Bridges RS 1984 A quantitative analysis of the roles of dosage, sequence, and duration of estradiol and progesterone exposure in the regulation of maternal behavior in the rat. Endocrinology 114 930-940. (doi:10.1210/ endo-114-3-930)

Brunton PJ 2010 Resetting the dynamic range of hypothalamic-pituitaryadrenal axis stress responses through pregnancy. Journal of Neuroendocrinology 22 1198-1213. (doi:10.1111/j.1365-2826.2010.02067.x)

Brunton PJ, Meddle SL, Ma S, Ochedalski T, Douglas AJ \& Russell JA 2005 Endogenous opioids and attenuated hypothalamic-pituitary-adrenal axis responses to immune challenge in pregnant rats. Journal of Neuroscience $\mathbf{2 5}$ 5117-5126. (doi:10.1523/JNEUROSCI.0866-05.2005)

Cao L, Wang J, Tseu I, Luo D \& Post M 2009 Maternal exposure to endotoxin delays alveolarization during postnatal rat lung development. American Journal of Physiology 296 L726-L737. (doi:10.1152/ajplung.90405.2008) 
Cui K, Ashdown H, Luheshi GN \& Boksa P 2009 Effects of prenatal immune activation on hippocampal neurogenesis in the rat. Schizophrenia Research 113 288-297. (doi:10.1016/j.schres.2009.05.003)

Dupouy JP, Coffigny H \& Magre S 1975 Maternal and foetal corticosterone levels during late pregnancy in rats. Journal of Endocrinology 65 347-352. (doi:10.1677/joe.0.0650347)

Fantuzzi G, Cantoni L, Sironi M \& Ghezzi P 1993 Inhibitors of cytochrome P450 suppress tumor necrosis factor production. Cellular Immunology 150 417-424. (doi:10.1006/cimm.1993.1209)

Fortier ME, Luheshi GN \& Boksa P 2007 Effects of prenatal infection on prepulse inhibition in the rat depend on the nature of the infectious agent and the stage of pregnancy. Behavioural Brain Research 181 270-277. (doi:10. 1016/j.bbr.2007.04.016)

Frank MG, Miguel ZD, Watkins LR \& Maier SF 2010 Prior exposure to glucocorticoids sensitizes the neuroinflammatory and peripheral inflammatory responses to E. coli lipopolysaccharide. Brain, Behavior, and Immunity 24 19-30. (doi:10.1016/j.bbi.2009.07.008)

Gower DB 1974 Modifiers of steroid-hormone metabolism: a review of their chemistry, biochemistry and clinical applications. Journal of Steroid Biochemistry 5 501-523. (doi:10.1016/0022-4731(74)90051-X)

Hermoso MA, Matsuguchi T, Smoak K \& Cidlowski JA 2004 Glucocorticoids and tumor necrosis factor alpha cooperatively regulate Toll-like receptor 2 gene expression. Molecular and Cellular Biology 24 4743-4756. (doi:10.1128/MCB.24.11.4743-4756.2004)

Jones LA, Anthony JP, Henriquez FL, Lyons RE, Nickdel MB, Carter KC, Alexander J \& Roberts CW 2008 Toll-like receptor-4-mediated macrophage activation is differentially regulated by progesterone via the glucocorticoid and progesterone receptors. Immunology 125 59-69. (doi:10. 1111/j.1365-2567.2008.02820.x)

Le Contel C, Beigneux AP, Huang J \& Parant MA 1995 Regulation of lipopolysaccharide-induced tumor necrosis factor production by cyclosporin A in mice primed with muramyl dipeptide. FEMS Immunology and Medical Microbiology 11 297-305. (doi:10.1111/j.1574-695X.1995. tb00160.x)

Liao J, Keiser JA, Scales WE, Kunkel SL \& Kluger MJ 1995 Role of corticosterone in TNF and IL-6 production in isolated perfused rat liver. American Journal of Physiology 268 R699-R706.

Lu YC, Yeh WC \& Ohashi PS 2008 LPS/TLR 4 signal transduction pathway. Cytokine 42 145-151. (doi:10.1016/j.cyto.2008.01.006)

Mairesse J, Lesage J, Breton C, Bréant B, Hahn T, Darnaudéry M, Dickson SL, Seckl J, Blondeau B, Vieau D et al. 2007 Maternal stress alters endocrine function of the feto-placental unit in rats. American Journal of Physiology 292 E1526-E1533. (doi:10.1152/ajprenal.00451.2006)

Martin SM, Malkinson TJ, Veale WL \& Pittman QJ 1995 Fever in pregnant, parturient, and lactating rats. American Journal of Physiology 268 R919-R923.

Meltzer JC, MacNeil BJ, Sanders V, Pylypas S, Jansen AH, Greenberg AH \& Nance DM 2003 Contribution of the adrenal glands and splenic nerve to LPS-induced splenic cytokine production in the rat. Brain, Behavior, and Immunity 17 482-497. (doi:10.1016/S0889-1591(03)00084-9)

Morrow LE, McClellan JL, Conn CA \& Kluger MJ 1993 Glucocorticoids alter fever and IL-6 responses to psychological stress and to lipopolysaccharide. American Journal of Physiology 264 R1010-R1016.

Perretti M, Duncan GS, Flower RJ \& Peers SH 1993 Serum corticosterone, interleukin-1 and tumour necrosis factor in rat experimental endotoxaemia: comparison between Lewis and Wistar strains. British Journal of Pharmacology 110 868-874.
Pettipher ER, Labasi JM, Salter ED, Stam EJ, Cheng JB \& Griffiths RJ 1996 Regulation of tumour necrosis factor production by adrenal hormones in vivo: insights into the antiinflammatory activity of rolipram. British Journal of Pharmacology 117 1530-1534.

Rivest S 2010 Interactions between the immune and neuroendocrine systems. Progress in Brain Research 181 43-53. (doi:10.1016/S0079-6123(08)81004-7)

Robertson SA, Christiaens I, Dorian CL, Zaragoza DB, Care AS, Banks AM \& Olson DM 2010 Interleukin-6 is an essential determinant of on-time parturition in the mouse. Endocrinology 151 3996-4006. (doi:10.1210/en. 2010-0063)

Rozkova D, Horvath R, Bartunkova J \& Spisek R 2006 Glucocorticoids severely impair differentiation and antigen presenting function of dendritic cells despite upregulation of Toll-like receptors. Clinical Immunology 120 260-271. (doi:10.1016/j.clim.2006.04.567)

Rummel C, Sachot C, Poole S \& Luheshi GN 2006 Circulating interleukin-6 induces fever through a STAT3-linked activation of COX-2 in the brain. American Journal of Physiology 291 R1316-R1326. (doi:10.1152/ajpregu. 00301.2006)

Schöbitz B, Van Den Dobbelsteen M, Holsboer F, Sutanto W \& De Kloet ER 1993 Regulation of interleukin 6 gene expression in rat. Endocrinology 132 1569-1576. (doi:10.1210/en.132.4.1569)

Scott HM, Mason JI \& Sharpe RM 2009 Steroidogenesis in the fetal testis and its susceptibility to disruption by exogenous compounds. Endocrine Reviews 30 883-925. (doi:10.1210/er.2009-0016)

Shibata M, Katsuyama M, Onodera T, Ehama R, Hosoi J \& Tagami H 2009 Glucocorticoids enhance Toll-like receptor 2 expression in human keratinocytes stimulated with Propionibacterium acnes or proinflammatory cytokines. Journal of Investigative Dermatology 129 375-382. (doi:10.1038/ jid.2008.237)

Simhan HN, Chiao JP, Mattison DR \& Caritis SN 2008 Human decidual cell Toll-like receptor signaling in response to endotoxin: the effect of progestins. American Journal of Obstetrics and Gynecology 198 119.e1-119.e4. (doi:10.1016/j.ajog.2007.06.022)

Sorrells SF \& Sapolsky RM 2007 An inflammatory review of glucocorticoid actions in the CNS. Brain, Behavior, and Immunity 21 259-272. (doi:10. 1016/j.bbi.2006.11.006)

Urakubo A, Jarskog LF, Lieberman JA \& Gilmore JH 2001 Prenatal exposure to maternal infection alters cytokine expression in the placenta, amniotic fluid, and fetal brain. Schizophrenia Research 47 27-36. (doi:10.1016/S09209964(00)00032-3)

Vagnerová K, Vacková Z, Klusonová P, Staud F, Kopecký M, Ergang P, Miksík I \& Pácha J 2008 Reciprocal changes in maternal and fetal metabolism of corticosterone in rat during gestation. Reproductive Sciences 15 921-931. (doi:10.1177/1933719108319161)

Wilson CA \& Davies DC 2007 The control of sexual differentiation of the reproductive system and brain. Reproduction 133 331-359. (doi:10.1530/ REP-06-0078)

Zhang TY \& Daynes RA 2007 Glucocorticoid conditioning of myeloid progenitors enhances TLR4 signaling via negative regulation of the phosphatidylinositol 3-kinase-Akt pathway. Journal of Immunology 178 $2517-2526$

Received in final form 13 January 2011

Accepted 17 January 2011

Made available online as an Accepted Preprint 17 January 2011 